\title{
Classification of previously unclassified cases of craniosynostosis
}

\section{Paul D. Chumas, F.R.C.S.(SN), Giuseppe Cinalli, M.D., Eric Arnaud, M.D., Daniel Marchac, M.D., and Dominique Renier, M.D.}

Service de Neurochirurgie, Hôpital Necker Enfants-Malades, Paris, France; and Department of Neurosurgery, The General Infirmary at Leeds, Leeds, England

Cases of craniosynostosis usually fall into well-demarcated categories: those related to a syndrome or identified by a combination of suture involvement and morphological appearance. Between 1976 and $1995,53(3.6 \%)$ of 1474 cases in the craniofacial databank were assessed and designated as

nonsyndromic but unclassifiable. The records and radiological studies obtained in these patients were retrospectively analyzed and comparisons were made with patients classified in the databank as having simple craniosynostoses.

It proved possible to divide the formerly unclassifiable cases into two groups: those with "two-suture disease" (Group A) and a "complex" group (Group B) in which more than two sutures were affected. Group A consisted of 36 cases $(68 \%)$ of patients presenting with clear evidence of simultaneous involvement of two sutures but with no progression over time to suggest a more diffuse pansynostosis. Suture involvement was as follows: 17 of 36 sagittal plus one coronal; seven of 36 sagittal plus metopic; six of 36 sagittal plus one lambdoid; and six of 36 metopic plus one coronal. The only significant difference between the Group A cases and the cases of simple craniosynostoses was in the percentage requiring a second operation $(24 \%$ vs. $5 \%, \mathrm{p}<0.0001)$.

Group B consisted of 17 cases in which the patients presented at a slightly earlier age (mean 1 year) with severe morphological changes and multiple suture involvement. At the time of surgery, six of 17 patients showed large areas of lacunae within the cranial vault, making craniectomy the only option. In Group B, 10 of 17 patients displayed bilateral lambdoid plus sagittal suture involvement resulting in marked occipital recession posteriorly, whereas anteriorly in six of these 10 patients there was a massive frontal bone associated with posteriorly located coronal sutures. In contrast, there were also four patients in Group B with bilateral coronal plus metopic involvement resulting in a small frontal bone. There was a trend toward a lower intelligence quotient and a worse morphological outcome in the patients in Group $\mathrm{B}$, but again the only result attaining statistical significance when compared to the databank was the rate of second operation $(37.5$ vs. $5 \%, \mathrm{p}<0.0001)$.

"Two-suture synostosis" is a relatively straightforward condition and is treatable with standard craniosynostosis techniques. However, possibly as a result of surgical compromise when two sutures are involved, the rate of reoperation is far higher than in simple suture cases. In contrast, patients in the "complex" group presenting with severe multisuture involvement require a more tailor-made approach to their management that often entails a second procedure. 
The classification of craniosynostoses depends on a combination of criteria: 1) whether the sutural disease is part of a syndrome; 2) the morphological appearance of the patient; 3) the actual sutures involved; and 4) progression of the disease over time.[1] Using these criteria, it is possible to classify the vast majority of craniosynostoses. In a minority of cases the initial classification proves to be incorrect and other features indicating a more complex nature become apparent. It is thus necessary to have a sufficient follow-up period to be confident that the initial diagnosis still holds.

Despite these criteria, some patients with nonsyndromic craniosynostoses prove impossible to classify. The aim of the present study was to review all patients assessed by the craniofacial team at the Hôpital Necker Enfants-Malades in Paris and designated as unclassifiable to determine whether there were any missed patterns of craniosynostosis in this group.

\section{CLINICAL MATERIAL AND METHODS}

Between 1976 and 1995, 1474 cases were registered in the craniofacial database at the Hôpital Necker Enfants-Malades. Of these, 1251 (85\%) were nonsyndromic craniosynostoses and have been classified as: scaphocephaly (592); trigonocephaly (172); plagiocephaly (190); brachycephaly (95); lambdoid synostosis (single or bilateral, 11); oxycephaly (129); and unclassifiable (62). The records and radiological studies of the 62 patients deemed unclassifiable were retrospectively analyzed. A comparison with the grouped results for all the other nonsyndromic craniosynostoses in the databank (1189 cases) was made for the following variables: age at diagnosis; suture involvement (derived from plain x-ray films and operative notes); mental development; type of operation; number of operations; and final morphological appearance. The classification of morphological appearance was determined by the surgical team at follow-up review and was assigned to one of the following categories: 1) excellent; 2) average; 3 ) poor (reoperation proposed); and 4) reoperation necessary. This morphological classification has been used in all patients seen for follow-up care and is therefore also available for all the single-suture and syndromic patients in the database. Previous work within our department (unpublished data) has shown that the assessment by the surgical team is significantly correlated with that of the lay public. For developmental assessment, the Brunet-Lezine scale was used for children younger than 3 years of age whereas those older than 3 years were assessed using the Nouvelle Echelle Metrique de l'Intelligence scale. Patients who showed progression of the disease over time with new suture involvement were excluded. Likewise, patients not initially treated at this institution and patients with an underlying metabolic disease were also excluded.

\section{RESULTS}

Nine patients were excluded: one who underwent initial treatment elsewhere, two whose syndromes were associated with metabolic disease, and six initially presenting with scaphocephaly but then showing evidence of progression of the disease to involve other sutures. This latter condition has been termed "progressive scaphocephaly" and is the subject of another report. 


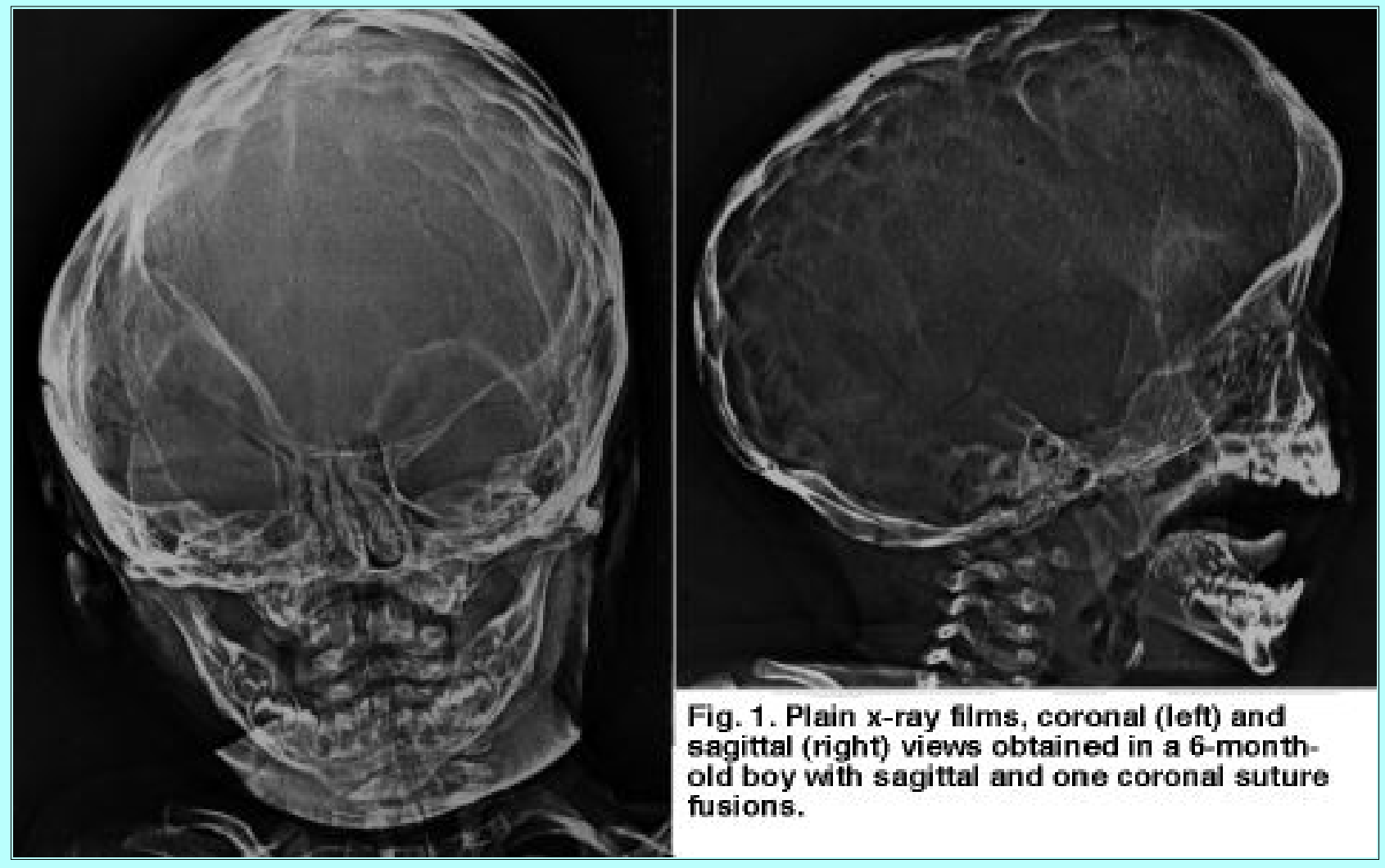

It proved possible to divide the remaining 53 cases into two groups: those with two-suture disease (Group A) and a complex group (Group B) in which more than two sutures were affected. Group A consisted of 36 cases (68\%), with all patients presenting with clear evidence of the simultaneous involvement of two sutures but with no progression over time to suggest a more diffuse pansynostosis. Suture involvement consisted of: 17 of 36 sagittal plus one coronal; seven of 36 sagittal and metopic; six of 36 sagittal plus one lambdoid; six of 36 metopic plus one coronal. There were 24 boys and 12 girls whose mean age at presentation was 1.2 years (range 19 days- 4.7 years). Preoperative intracranial pressure (ICP) monitoring was performed in nine patients (mean $13.9 \mathrm{~mm} \mathrm{Hg}$, range 10-20 $\mathrm{mm} \mathrm{Hg}$ ) and the mean preoperative developmental assessment (performed on 18 patients) was 93 (range 70-117). 


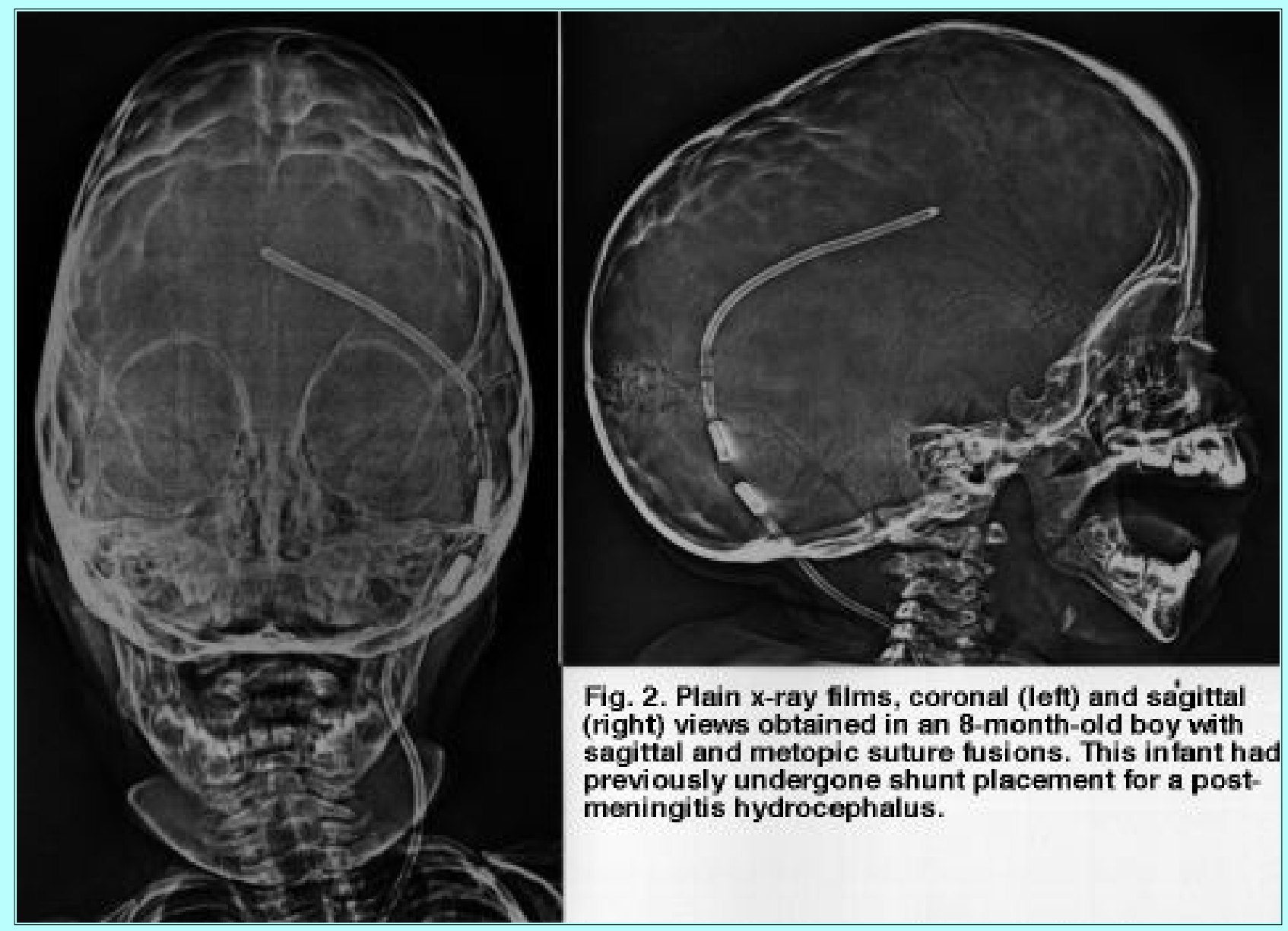

No surgery was performed in three patients. Among the remaining 33 cases, a single operation was required in 25 patients, repeat operations were required in seven, and a third operation in one. The mean follow-up duration among the patients undergoing operation was 4.1 years (median 3.3 years). Mean intelligence quotient (IQ) at follow-up review was 99.6 (range 20-131). Postoperative morphological assessment was graded as excellent in 12 , mediocre in 12 , reoperation mandatory in two, and was not assessed in seven patients. The only significant difference between patients in this group and those with simple craniosynostoses was in the percentage requiring a second operation: $24 \%$ versus $5 \%(\mathrm{p}<0.0001$, one-way analysis of variance). Figs. 1 to 4 give examples of all the types of two-suture disease. 


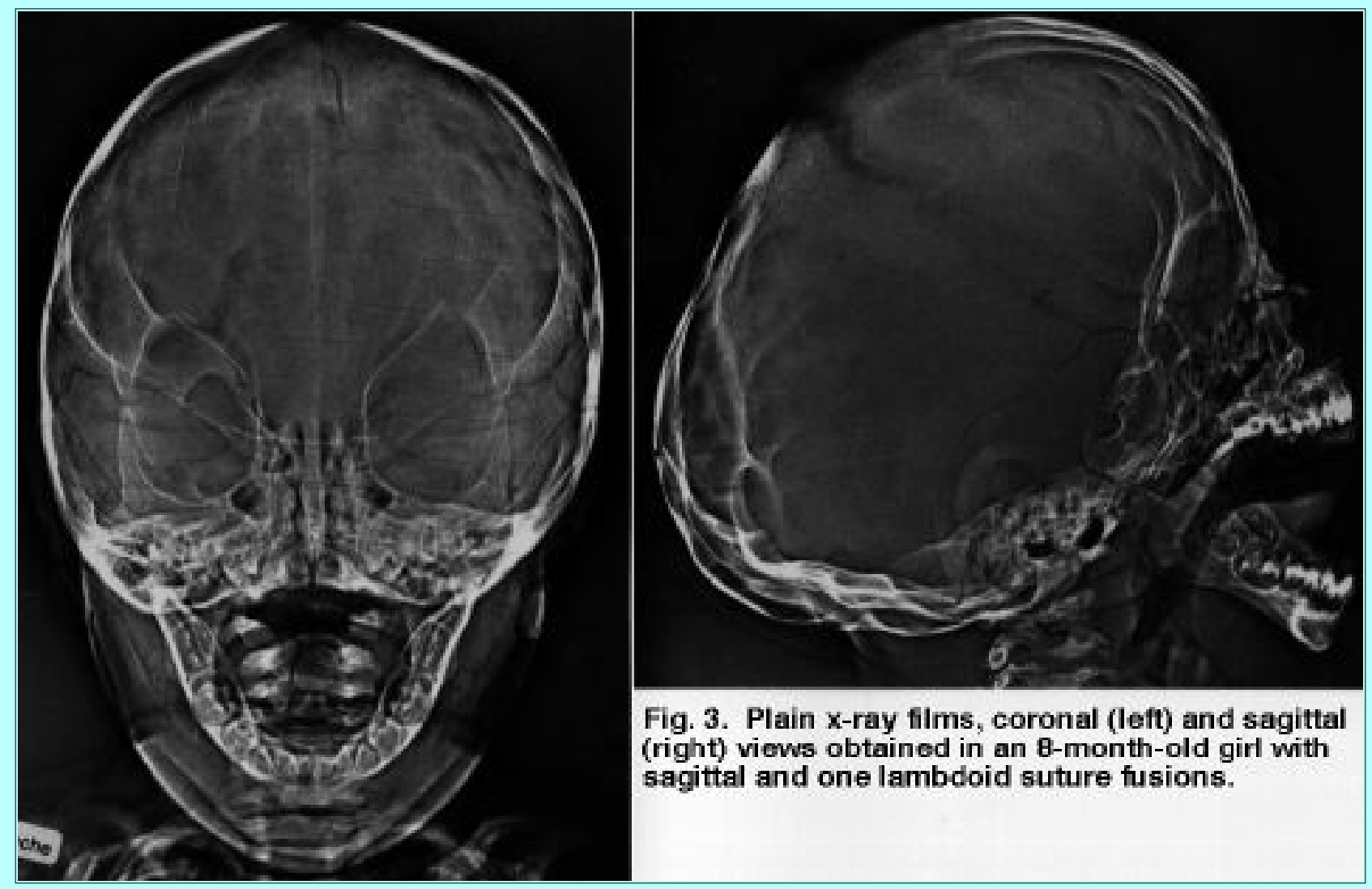

Group B consisted of 17 cases (32\%), and these patients presented at a slightly earlier age (mean 1 year, range 33 days-7.7 years) with severe morphological changes and multiple suture involvement. The male/female ratio was 12:5. Only two patients underwent ICP monitoring because in most of the other cases there was sufficient clinical evidence to warrant surgery. One pressure tracing was normal, whereas the other exhibited a baseline exceeding $15 \mathrm{~mm} \mathrm{Hg}$. Neither of these patients showed evidence of raised ICP or papilledema on x-ray films. Developmental assessment was performed preoperatively in five patients (mean 94, range 72-100). All but one patient underwent surgical correction, and at the time of surgery six of 17 had large areas of lacunae within the cranial vault with protruding dural hernias that rendered craniectomy as the only option. 


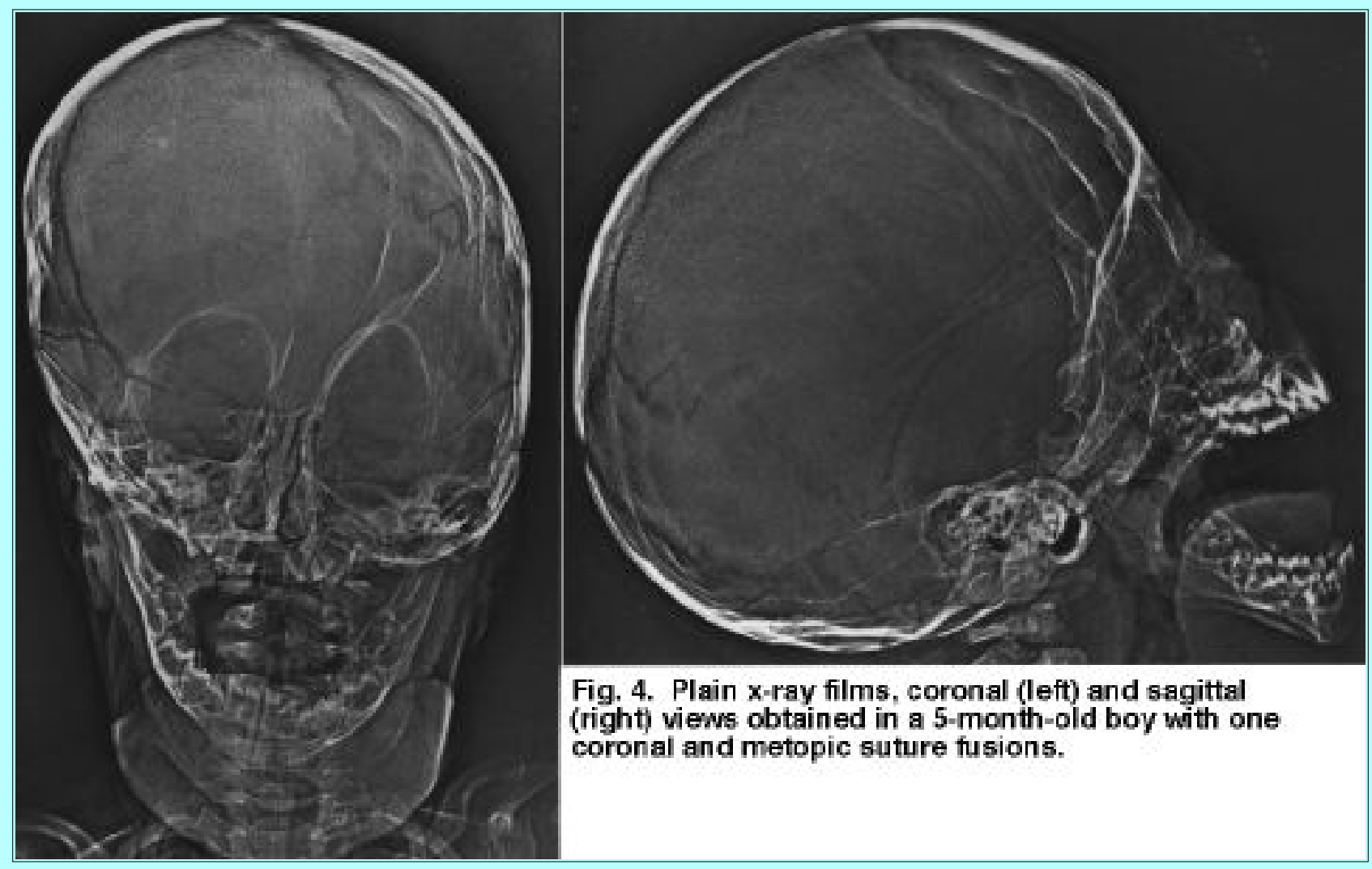

It proved possible to subdivide Group B in the following fashion: 1) bilateral lambdoid plus sagittal suture involvement resulting in marked posterior recession of the skull was noted in 10 of 17 cases. In six of these 10 cases the coronal sutures were posteriorly placed resulting in a large frontal bone (Fig. 5). The remaining four patients showed the acute posterior angulation, but two showed temporal bossing in addition (Fig. 6). 2) Also within this group of patients in whom more than two sutures were affected were four with bilateral coronal plus metopic involvement, a combination giving rise to a tiny frontal bone (Fig. 7). 3) There were three patients in whom there were widespread lacunae that made it impossible to comment on the suture involvement on x-ray films or at the time of surgery (Fig. 8). 


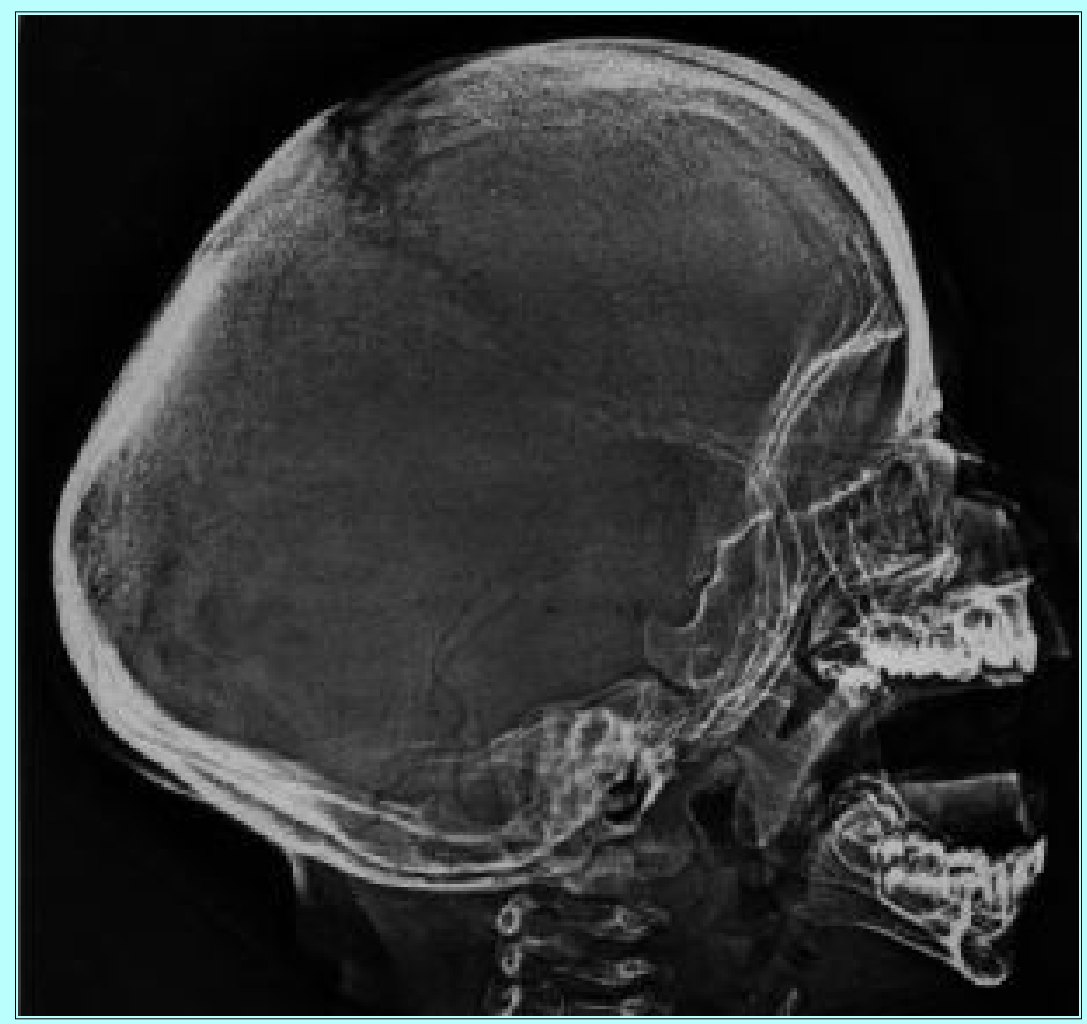

Fig. 5. Plain x-ray film obtained in a 10-month-old boy with sagittal and both lambdoid suture fusions.

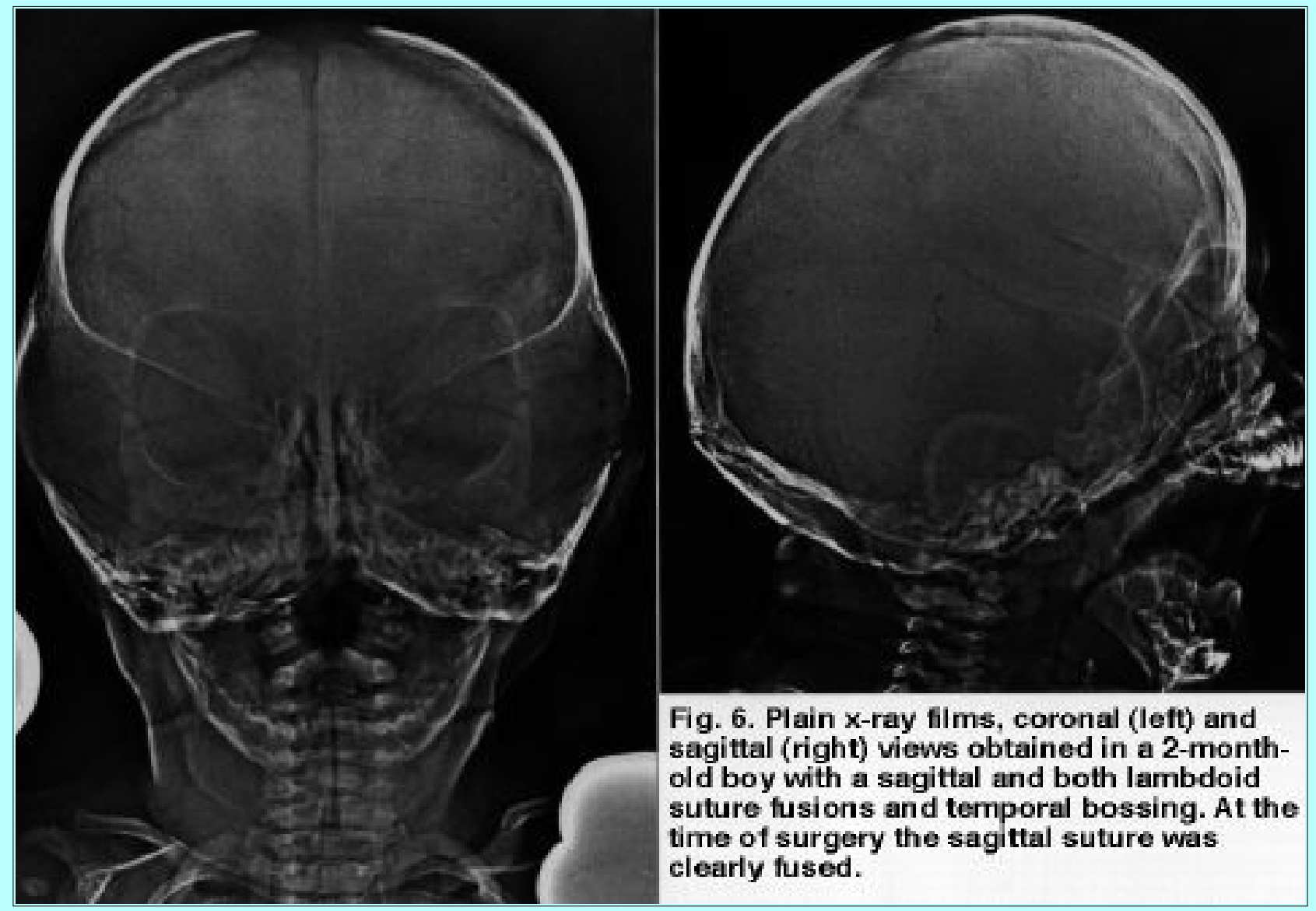




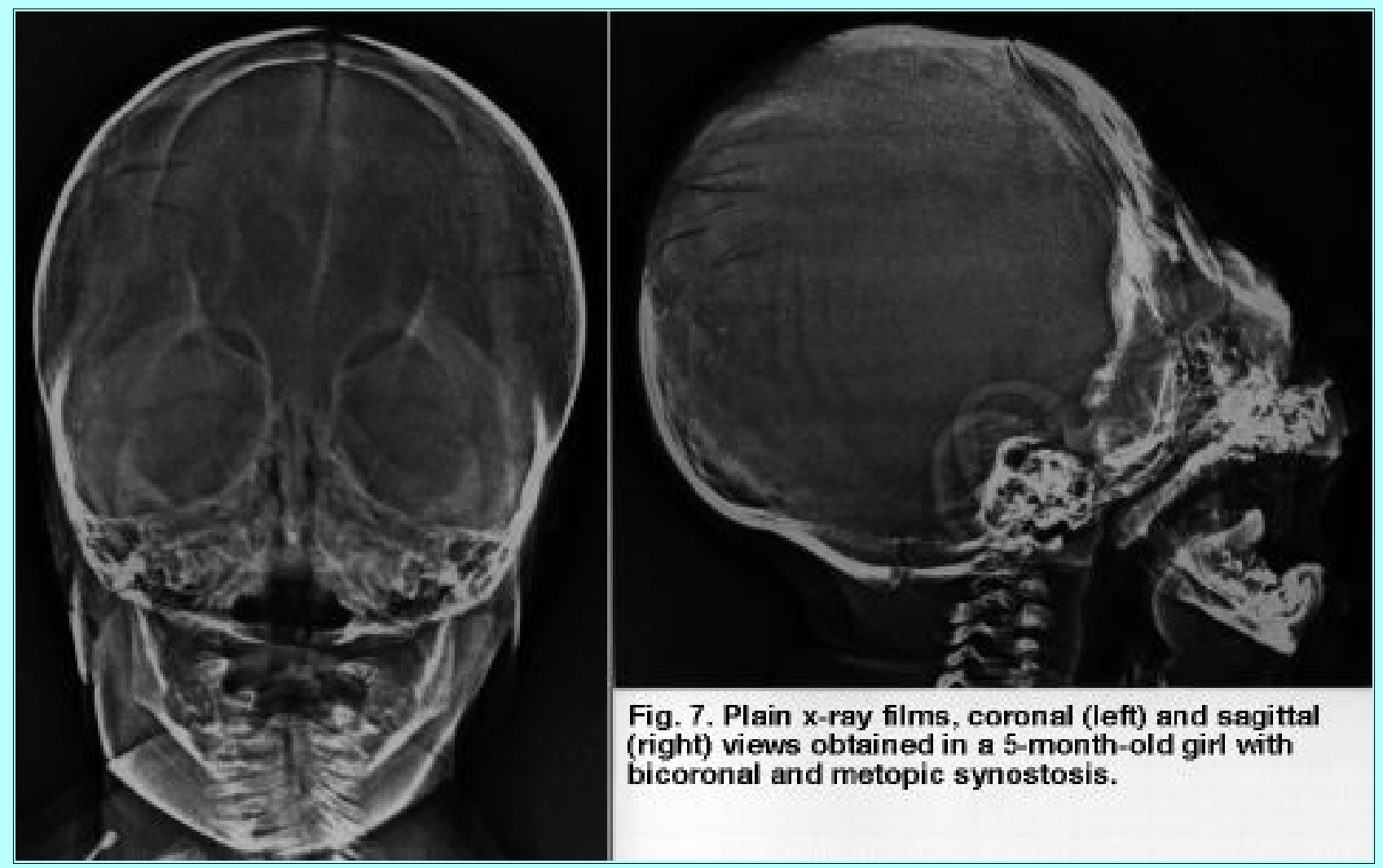

The mean follow-up period for the surgically treated patients in Group B (mean IQ of 89.8, range 58-122) was 5.5 years (median 4.6 years). In 10 patients only one procedure was necessary, whereas six patients needed a second procedure. Morphological outcome was graded as excellent in four, mediocre in nine, reoperation mandatory in two, and unknown in one case. Although there was a trend toward a lower IQ and a worse morphological outcome in Group B patients, again the only figure to attain significance when compared to the nonsyndromic patients in the databank was the rate of second operation (37.5\% vs. $5 \%, \mathrm{p}<0.0001$, one-way analysis of variance).
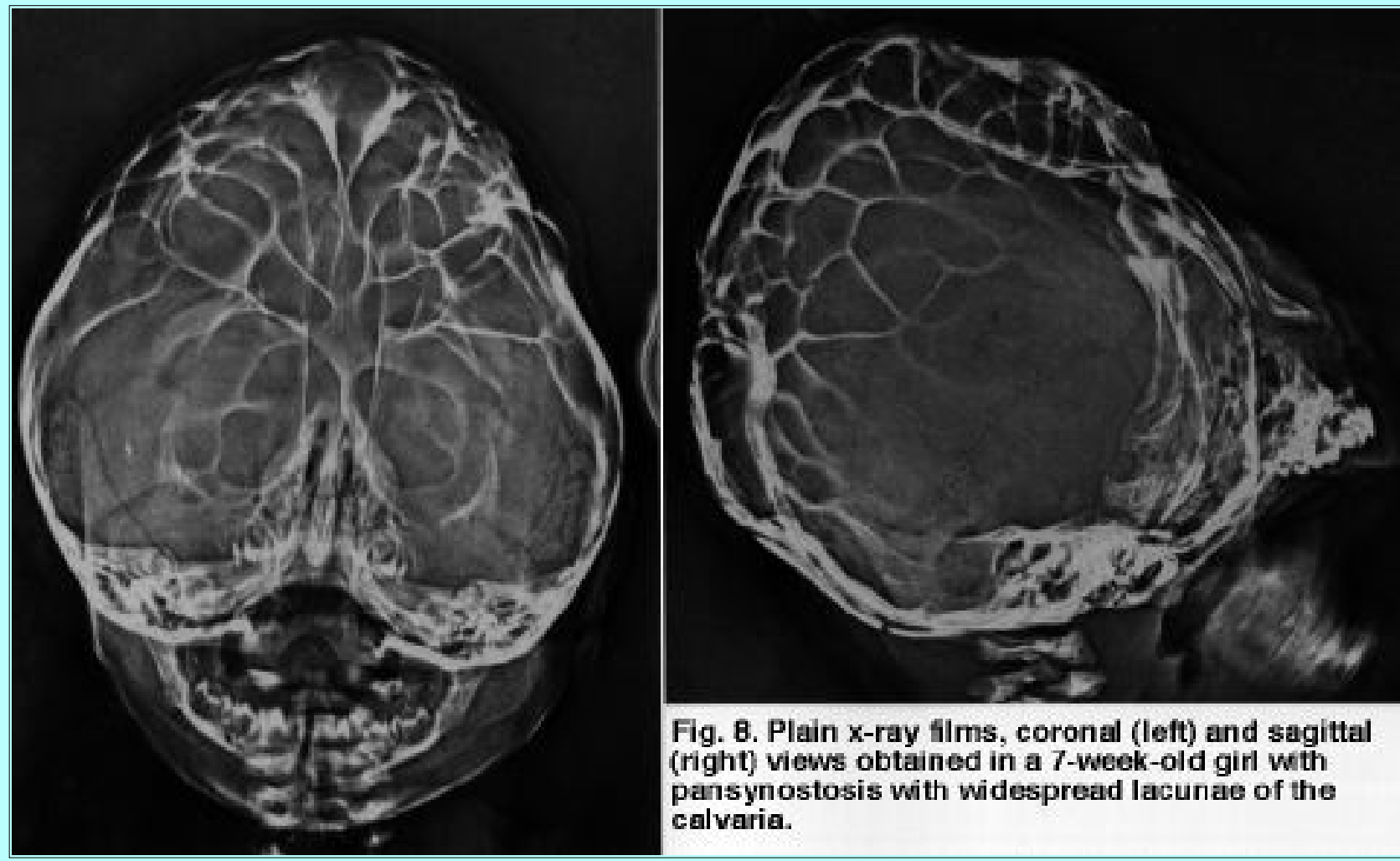

Fig. 8. Plain x-ray films, coronal (left) and sagittal (right) views obtained in a 7-week-old girl with pansynostosis with widespread lacunae of the calvaria. 


\section{DISCUSSION}

Unclassifiable craniosynostoses are rare, representing less than 5\% of nonsyndromic cases of craniosynostsis in our series. In the present study, it proved possible to classify these as cases showing various forms of two-suture disease (Group A) and as those with various forms of complex craniosynostoses (Group B). The advantages of centralizing the assessment and treatment of patients with craniosynostoses are that it allows for the development of clinical expertise and also for the collection of sufficient data for pattern recognition of what would otherwise be case report material. In the Toronto series[4] multiple suture synostoses accounted for $7.6 \%$ of cases of craniosynostosis not associated with craniofacial dysmorphism.

\section{Two-Suture Disease}

Approximately two-thirds of unclassifiable craniosynostoses could be assigned to Group A. Obviously, bilateral coronal synostosis (brachycephaly) is the most common form of two-suture disease and has been recognized since ancient times.[1] The present study shows that there are other recognizable two-suture states. Among these, involvement of the sagittal suture occurred in 83\%, coronal in $64 \%$, metopic in $36 \%$, and lambdoid in $17 \%$. Also of note is the fact that all the sutures involved were contiguous. This, and the lack of familial cases in this group, may be evidence supporting mechanical factors in utero rather than genetic makeup as the most important etiological factor.[2,3,5]

Although there are very few reports in the literature with which to compare our group of patients, others have shown examples of similar cases; for example, McComb and Raffel[7] show a photograph of a child with unilateral coronal and lambdoid synostosis (a combination that is noncontiguous and one that we have not witnessed) in their chapter on the management of craniosynostoses. In fact, in view of the noncontiguous nature of this case, we believe that this may in fact represent unicoronal synostosis and posterior positional molding.

\begin{tabular}{|c|c|c|c|}
\hline $\begin{array}{l}\text { RATES OF SURGKCAL INT } \\
\text { COMFLEX DISEASE }\end{array}$ & $\begin{array}{l}\text { TABLE } \\
\text { ENTION IN } 53 \\
\text { PATIENTS WITT }\end{array}$ & IENTS WITH & $\begin{array}{l}\text { O-SUTURE OR } \\
\text { NOTOSE }\end{array}$ \\
\hline & & Type of Diseas & \\
\hline Factor & Two-Suture & Complex & $\begin{array}{l}\text { Grouped Nort } \\
\text { syndromic }\end{array}$ \\
\hline $\begin{array}{l}\text { no. of cases } \\
\text { age at presentation (yrs) } \\
\text { preop DQ (no. of pts) } \\
\text { preop ICP (no. of pts) } \\
\text { no. treated surgically (\%) } \\
\text { follow-up period (yrs) }\end{array}$ & $\begin{array}{c}36 \\
1.2 \pm 1.3 \\
93 \pm 13(18) \\
13.9(9) \\
33(92 \%) \\
4.1 \pm 3.1\end{array}$ & $\begin{array}{c}17 \\
1 \pm 1.9 \\
94 \pm 12(5) \\
10(2) \\
16 .(94 \%) \\
5.5 \pm 5.1\end{array}$ & $\begin{array}{c}1189 \\
1.3 \pm 1.9 \\
99 \pm 14(701) \\
10.6(428) \\
903(76 \%) \\
4 \pm 3.5\end{array}$ \\
\hline $\begin{array}{l}\text { no. of operations } \\
\text { one } \\
\text { two } \\
\text { three } \\
\text { final IO (no. of pts) } \\
\text { final morphological grade }\end{array}$ & $\begin{array}{c}25 \mathrm{pts}(76 \%) \\
7 \mathrm{pts} \\
1 \mathrm{pt} \\
99 \pm 24(25) \\
1.6 \pm 0.6\end{array}$ & $\begin{array}{c}10 \mathrm{pts}(62 \%) \\
6 \mathrm{pts} \\
90 \pm 20(13) \\
1.9 \pm 0.6\end{array}$ & $\begin{array}{c}858 \mathrm{pts}(95 \%) \\
42 \mathrm{pts} \\
3 \mathrm{pts} \\
101 \pm 17(737) \\
1.3 \pm 0.6\end{array}$ \\
\hline
\end{tabular}

The results displayed in Table 1 show that when compared with simple craniosynostoses a higher percentage of patients with two-suture disease undergo surgical intervention, they more frequently 
require reoperation $(\mathrm{p}<0.001)$, and there is a trend for the surgery to be less successful, with a worse final morphological outcome. We believe that these findings are the result of the surgical compromise that is necessary when treating two sutures simultaneously. Nonetheless, our standard craniofacial techniques were used to treat these patients.[6]

\section{Complex Craniosynostosis}

Three morphological features were found to define this group of patients with multiple suture involvement (Group B). The first was the presence of lacunae in the skull (seen in six of 17), which made the operation technically far more demanding and limited the type of surgery that could be performed. Lacunae have been documented previously in cases of severe craniosynostosis.[9]

The second feature was the acute angle of the posterior skull that is seen in patients with bilateral lambdoid synostosis; the French term "coup de serpe" (cut by a scythe) is used to describe this acute angle. Ten of the 17 patients had the coup de serpe deformity in association with sagittal synostosis, six with a large frontal bone and four with a normal-size frontal bone (of which two showed temporal bossing). Again, this type of deformity has been seen previously; a photograph of the coup de serpe deformity in a patient with Crouzon's syndrome was used by Hoffman and Raffel[4] in their chapter on craniofacial surgery. Although lambdoid synostosis (unilateral or bilateral) represents only $1 \%$ of the nonsyndromic cases in our series, there is obviously a marked increase in lambdoid involvement among all the previously unclassified cases (30\%). The diagnosis of lambdoid involvement in these cases was made on the basis of radiographic evidence of absence of the sutures, and this was confirmed at the time of surgical intervention. The low frequency of lambdoid synostosis seen in our series is further evidence of the strict criteria used in our department to make this diagnosis and to differentiate it from posterior positional molding.

The third feature was seen in the small group of four patients exhibiting bicoronal and metopic synostosis, a combination resulting in marked anterior deformity and a vestigial frontal bone. This rare condition is often misdiagnosed as oxycephaly, which in fact is completely different, the latter being a late-appearing bicoronal synostosis with a backward tilted but normally sized forehead.[8]

Again, analyzing Table 1 shows that the age at presentation is slightly lower and that the rate of surgical intervention in this group is exceedingly high, a reflection of the presence of the cranial lacunae and the gross morphological findings. Not surprisingly, the rate of reoperation is also high and there is a trend toward a worse morphological outcome and poorer mental development.

\section{Rate of Reoperation}

It can thus be seen that in patients with two-suture disease and in the complex group the rate of reoperation is significantly higher than in those nonsyndromic patients with single suture disease. The need for a repeat procedure was not due to failure to recognize that more than one suture was involved at presentation, but to poor morphological results or the recurrence of evidence of raised ICP. Whereas standard craniofacial techniques were used in most cases, in the presence of widespread lacunae craniectomy alone was often the only available treatment, despite its known limitations.

\section{References}

1. Cohen MM Jr: History, terminology, and classification of craniosynostosis, in Cohen MM Jr (ed): 
Craniosynostosis: Diagnosis, Evaluation, and Management. New York: Raven Press, 1986

2. Graham JM Jr, deSaxe M, Smith DW: Sagittal craniostenosis: fetal head constraint as one possible cause. J Pediatr 95:747-750, 1979

3. Higginbottom MC, Jones KL, James HE: Intrauterine constraint in craniosynostosis. Neurosurgery 6:39-44, 1980

4. Hoffman H, Raffel C: Craniofacial surgery, in McLaurin R, Venes JL, Schut L, et al. (eds): Pediatric Neurosurgery. Surgery of the Developing Nervous System. Philadelphia: WB Saunders, 1989

5. Lajeunie E, Le Merrer M, Bonaiti-Pellie C, et al: Genetic study of scaphocephaly. Am J Med Genet 62:282-285, 1996

6. Marchac D, Renier D: Craniofacial Surgery for Craniosynostosis. Boston: Little, Brown and Co, 1982

7. McComb JG, Raffel C: Craniosynostosis, in Apuzzo MLJ (ed): Brain Surgery. Complication Avoidance and Management. New York: Churchill Livingstone, 1993, pp 1449-1462

8. Renier D, Marchac D: Oxycephaly: an often complex diagnosis with a review of surgical management, in Goodrich JT, Hall CD (eds): Craniofacial Anomalies: Growth and Development From a Surgical Perspective. New York: Thieme, 1995, pp 56-64

9. Saal HM, Bulas DI, Allen JF, et al: Patient with craniosynostosis and marfanoid phenotype (Shprintzen-Goldberg Syndrome) and cloverleaf skull. Am J Med Genet 57:573-578, 1995

Manuscript received February 23, 1996.

Accepted in final form September 12, 1996.

Address reprint requests to: Dominique Renier, M.D., Service de Neurochirurgie, Hôpital Necker Enfants-Malades, 149, rue de Sèvres, Paris 75743, Cedex 15 France. 